\title{
Abstinence from Cocaine-Induced Conditioned Place Preference Produces Discrete Changes in Glutamatergic Synapses onto Deep Layer 5/6 Neurons from Prelimbic and Infralimbic Cortices
}

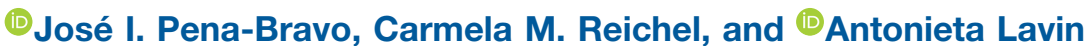

DOI:http://dx.doi.org/10.1523/ENEURO.0308-17.2017

Department of Neuroscience, Medical University of South Carolina, Charleston, SC 29425

\begin{abstract}
Glutamatergic signaling in the medial prefrontal cortex (mPFC) plays a critical role in drug addiction and relapse. The mPFC is functionally subdivided into dorsal (prelimbic, PL) and ventral (infralimbic, IL) regions, and evidence suggests a differential role of these two divisions in the control of drug seeking and taking; however, there is a dearth of information on the cocaine-induced adaptations in PL- and IL-mPFC synaptic glutamate transmission and their regulation of behavioral responses to cocaine-associated stimuli. We tested male rats in a cocaine-induced conditioned place preference (CPP) paradigm. In vitro whole-cell recordings were performed at different abstinence intervals to investigate the neuroadaptations in synaptic glutamate transmission in PL- and IL-mPFC deep layer (5/6) pyramidal neurons. Our results show that in naïve animals, PL-mPFC neurons expressed higher frequency of spontaneous events (sEPSCs) than IL-mPFC neurons. Following cocaine-CPP and a short abstinence (SA) period (8 d), we observed decreases in the amplitude of sEPSCs in both mPFC regions. Longer abstinence periods (30 d), resulted in a sustained decrease in the frequency of SEPSCs and an increase in AMPA receptor rectification only in PL-mPFC neurons. In addition, PL-mPFC neurons expressed a decrease in the area under the curve of sEPSCs, suggesting altered receptor activation dynamics. Synaptic glutamate transmission was not significantly different between retested and naïve rats. These results suggest that retention of cocaine-CPP requires differential modulation of glutamate transmission between PL- and IL-mPFC neurons and that these adaptations are dependent on the abstinence interval and reexposure to the cocaine context.
\end{abstract}

Key words: cocaine; glutamate; memory; neuroadaptations; prefrontal cortex; synaptic

\section{Significance Statement}

Addicted individuals have cognitive impairments associated with abnormal prefrontal cortex (PFC) function. Preclinical studies suggest that prelimbic (PL)- and infralimbic (IL)-medial PFC (mPFC) glutamatergic output neurons play opposing roles in the control of addiction-related behaviors. Therefore, we used PFC slice recordings from male rats after abstinence from cocaine-conditioned place preference (CPP) to measure the cocaine-evoked changes in glutamate transmission. We show for the first time that in naïve rats, PL-mPFC neurons exhibit a higher frequency of spontaneous excitatory currents compared to IL-mPFC neurons. In addition, synaptic glutamate transmission is selectively altered in rats that are not exposed to the conditioning context; and prolonged abstinence (PA) from cocaine-CPP produces an overall increase in the kinetics of spontaneous excitatory currents. Reversing these glutamate changes might prevent retention of cocaine-context associations. 


\section{Introduction}

Addiction treatment studies have demonstrated the need for novel biomarkers that target the symptoms associated with abstinence from drug use (Sinha, 2011). The prefrontal cortex (PFC) processes information relevant for the regulation of addiction-related behaviors, such as: impulse inhibition, behavioral monitoring, and decisionmaking; among other behaviors (Mansouri et al., 2009; Goldstein and Volkow, 2011; Kim and Lee, 2011; Coutlee and Huettel, 2012). In addicted individuals, the loss of control over drug taking despite negative consequences is one of the most significant symptoms and suggests cognitive deficits associated with abnormal PFC activity (for a review, see Goldstein and Volkow, 2011). Similarly, preclinical studies in rodents have demonstrated that cognitive dysfunction following prolonged cocaine exposure is mediated by altered PFC activity (Briand et al., 2008; George et al., 2008; Ghasemzadeh et al., 2011).

The role of the glutamatergic projections from medial PFC (mPFC) to the nucleus accumbens (NAc) in mediating cocaine seeking behavior has been extensively studied (McFarland et al., 2003; Stefanik et al., 2013; Gipson et al., 2014; McGlinchey et al., 2016; Stefanik et al., 2016). Indeed, in rats trained to self-administer cocaine followed by extinction of the operant response, activity in the prelimbic mPFC (PL-mPFC) was been shown to drive cocaine-seeking behavior, while the infralimbic mPFC (IL$\mathrm{mPFC}$ ) plays an opposite role (McLaughlin and See, 2003; Peters et al., 2008; Van den Oever et al., 2010; LaLumiere et al., 2012). These discrete PFC subregions send glutamatergic projections to specific targets in the ventral striatum. PL-mPFC projections innervate mainly the core of the NAc while IL-mPFC projections target the shell of the NAc (Heidbreder and Groenewegen, 2003; Vertes, 2004).

Whereas much of the research on cocaine addiction has focused on the NAc, less is known about long-term synaptic changes occurring in MPFC pyramidal projection neurons as a consequence of the reinforcing properties of a cocaine-associated context. We hypothesize that neurons within the PL-mPFC will express a strengthening of synaptic transmission that promotes the retention of the cocaine-context associations. In contrast, IL-mPFC neurons will show no change in glutamatergic synaptic markers, suggesting a mPFC subregion-specific enhancement of synaptic glutamate transmission in cocaine-context

Received September 5, 2017; accepted November 22, 2017; First published December 04, 2017.

The authors declare no competing financial interests.

Author contributions: J.I.P.-B., C.M.R., and A.L. designed research; J.I.P.-B. performed research; J.I.P.-B., C.M.R., and A.L. analyzed data; J.I.P.-B., C.M.R., and A.L. wrote the paper.

This work was supported by the National Institute of Drug Abuse Grant T32DA007288-21 (to J.I.P.-B.).

Correspondence should be addressed to Dr. Antonieta Lavin, Department of Neuroscience, Medical University of South Carolina, 173 Ashley Avenue, Suite 403 BSB, Charleston, SC 29425. E-mail: lavina@musc.edu.

DOI:http://dx.doi.org/10.1523/ENEURO.0308-17.2017

Copyright (C) 2017 Pena-Bravo et al.

This is an open-access article distributed under the terms of the Creative Commons Attribution 4.0 International license, which permits unrestricted use, distribution and reproduction in any medium provided that the original work is properly attributed. associations. The following study used whole-cell electrophysiological recordings from deep layer $5 / 6$ pyramidal neurons in rats that underwent cocaine-induced conditioned place preference (CPP), followed by different abstinence intervals, to understand the differences in synaptic glutamate neuroadaptations between PL- and ILmPFC neurons. These findings will inform the differential impact cocaine has in the mPFC and the particular role each region plays in mediating the reinforcing effects of a cocaine-conditioned context.

\section{Materials and Methods}

\section{Laboratory animals}

Subjects were adult male Sprague-Dawley rats (Harlan), weighing 250-275 g on arrival. Rats were pairhoused in a temperature-controlled colony room on a 12/12 h light/dark cycle with food and water available ad libitum. All procedures were conducted in accordance with the Guide for the Care and Use of Laboratory Rats (Institute of Laboratory Animal Resources on Life Sciences, National Research Council) and approved by the Institutional Animal Care and Use Committee of the Medical University of South Carolina.

\section{Apparatus}

A three-compartment chamber $(68 \times 21 \times 21 \mathrm{~cm}$; ENV-013; MED Associates) was used to assess CPP. The chamber had manual sliding guillotine doors to separate the three compartments. The neutral compartment in the middle $(12 \times 21 \times 21 \mathrm{~cm})$ had gray walls and floor. The end compartments had the same dimensions $(28 \times 21 \times$ $21 \mathrm{~cm}$ ), with the left compartment having black walls with a stainless-steel grid rod floor and the right compartment having white walls with a stainless-steel mesh floor. A computer controlled the CPP test using Med-IV software. A series of infrared photobeams (six beams in the black and white compartments and three beams in the gray compartment) were used to record the amount of time spent in each compartment.

\section{Cocaine place preference}

On habituation day (day 0), all rats were allowed to roam the three compartments of the CPP apparatus for $10 \mathrm{~min}$. This habituation day was used as a preconditioning (PC) test to verify the unbiased construction of the apparatus. Conditioning compartments were assigned in an unbiased manner such that each rat had equal opportunity to receive cocaine in their naturally least or most preferred side (Mueller and Stewart, 2000; Tzschentke, 2007; Reichel et al., 2010). Placements were counterbalanced according to chamber color (black/white) and whether the rats received cocaine or saline injections on the first or second day of conditioning. Six cohorts of rats were used in this study and a group of saline-treated (Control rats (Ctrl): cocaine naïve) rats was included in each cohort. Rats were conditioned for $8 \mathrm{~d}$ with 24-h intervals between sessions. During conditioning, rats were restricted to either the black or white side for 25 min. During odd days (days 1, 3, 5, and 7) of conditioning, rats placed in their paired compartment (CS + ) were injected with cocaine (20 
$\mathrm{mg} / \mathrm{kg}$ ) and rats placed in their unpaired compartment (CS-) received a saline injection immediately before compartment placement. During even days (days 2, 4, 6, and 8) of conditioning, treatments were alternated, and rats were placed in the opposite compartment for $25 \mathrm{~min}$. Rats in the saline group were injected with cocaine during both odd and even days. On the test day (day 9), rats from the saline and cocaine conditioned groups were injected with saline and were allowed to explore the entire apparatus for $10 \mathrm{~min}$. Time spent in each compartment was recorded and evaluated. On successful expression of a place preference, rats were randomly assigned to an abstinence group [short abstinence (SA): $8 \mathrm{~d}$ after the initial CPP test or prolonged abstinence (PA): at least $30 \mathrm{~d}$ after the initial CPP test] and were tested for CPP $(+)$ or remained in their home cages (-) for $24 \mathrm{~h}$, after which time, the brains were dissected and mPFC slices were prepared for patch-clamp electrophysiology experiments (Fig. 1A). Saline rats (Ctrl) remained in their home cages for $8 \mathrm{~d}(\mathrm{SA})$ following the initial preference test and were allowed to explore the CPP apparatus $10 \mathrm{~min}$ before tissue processing for electrophysiology experiments (Fig. $1 A)$.

\section{Brain slice preparation and electrophysiology}

Saline or cocaine-treated rats were deeply anesthetized with isoflurane, brains were removed, and coronal PFC slices $(300 \mu \mathrm{m})$ were cut on a vibratome (Leica, VT1200S) in ice-cold sucrose-containing ACSF: $200 \mathrm{mM}$ sucrose, $1.9 \mathrm{mM} \mathrm{KCl}, 1.2 \mathrm{mM} \mathrm{Na}_{2} \mathrm{HPO}_{4}, 33 \mathrm{mM} \mathrm{NaHCO}$, $6 \mathrm{mM}$ $\mathrm{MgCl}_{2}, 0.5 \mathrm{mM} \mathrm{CaCl}_{2}, 10 \mathrm{mM}$ D-glucose, and $0.4 \mathrm{mM}$ ascorbic acid. Slices were incubated at $32^{\circ} \mathrm{C}$ for at least 1 $\mathrm{h}$ in a solution consisting of $120 \mathrm{mM} \mathrm{NaCl}, 2.5 \mathrm{mM} \mathrm{KCl}$, $1.25 \mathrm{mM} \mathrm{NaH}_{2} \mathrm{PO}_{4}, 25 \mathrm{mM} \mathrm{NaHCO}_{3}, 4 \mathrm{mM} \mathrm{MgCl}_{2}, 1 \mathrm{mM}$ $\mathrm{CaCl}_{2}, 10 \mathrm{mM}$ D-glucose, and $0.4 \mathrm{mM}$ ascorbic acid. Then the slices were transferred to a recording chamber. Recordings were performed at room temperature using a recording ACSF consisting of $126 \mathrm{mM} \mathrm{NaCl}, 2.5 \mathrm{mM} \mathrm{KCl}$, $1.4 \mathrm{mM} \mathrm{NaH}_{2} \mathrm{PO}_{4}, 25 \mathrm{mM} \mathrm{NaHCO} 3,2.0 \mathrm{mM} \mathrm{CaCl}, 1.3$ $\mathrm{mM} \mathrm{MgCl}, 10 \mathrm{mM}$ D-glucose, and $0.4 \mathrm{mM}$ ascorbic acid at a rate of $2-3 \mathrm{ml} / \mathrm{min}$. All ACSF solutions were constantly aerated with a mixture of $95 \% \quad \mathrm{O}_{2}-5 \% \quad \mathrm{CO}_{2}(\mathrm{pH} 7.2$, 300-310 mOsm).

Whole-cell voltage-clamp recordings were obtained from visually identified pyramidal neurons in layers $5 / 6$ of the PL-mPFC and IL-mPFC using differential interference contrast optics (Axioskop 2, Zeiss) attached to a camera (Dage-MTI). Recordings electrodes (2.5-3 MOhm pipette resistance) were filled with $130 \mathrm{mM} \mathrm{CsCl}, 10 \mathrm{mM}$ HEPES, $2 \mathrm{mM} \mathrm{MgCl}, 0.5 \mathrm{mM}$ EGTA, $2 \mathrm{mM} \mathrm{Na} \mathrm{m}_{2}$ ATP, $0.3 \mathrm{mM}$ Na-GTP, $2 \mathrm{mM}$ QX-314, $10 \mathrm{mM}$ phosphocreatine, and 0.1 $\mathrm{mM}$ spermine; 290 mOsmol.

\section{Data collection and analysis}

Time spent in each compartment was recorded with Med Associates software on the preference (CPP), SA, and PA tests. Data were converted into a preference ratio to definitively assert a compartment preference. The ratio was calculated with the following formula: [(time in CS+/ (time in CS- + CS +)) $\times 100$ ] (Reichel and Bevins, 2008). Saline control rats values were randomly assigned a CS + and CS- compartment for comparison purposes (Reichel et al., 2010). Preference ratios were then compared against a hypothetical mean of $50 \%$. A preference score of $50 \%$ indicated a lack of compartment preference; a value $>50 \%$ indicated a preference for the drug paired compartment. Rats that failed to show a preference ratio $>50 \%$ were excluded from the study $(n=8)$.

Electrophysiological recordings were obtained with a Multiclamp 700B amplifier (Molecular Devices). Signals were low-pass filtered at $3 \mathrm{kHz}$ and digitized at $10 \mathrm{kHz}$. Data were stored on PC for off-line analysis. Data acquisition was performed using Axograph- $X$ software (J. Clements). Analysis of spontaneous EPSCs (sEPSCs) and evoked EPSCs (eEPSC) peak amplitude data were done in Mini Analysis (v6.0.7; Synaptosoft). Each parameter was measured in the following order: (1) SEPSCs and (2) AMPA-eEPSC/rectification index (RI). (1) Briefly, membrane potential was held at $-70 \mathrm{mV}$, and glutamatemediated events were pharmacologically isolated by adding picrotoxin $(50 \mu \mathrm{M})$ to the bath. Series resistance (Rs) was continuously monitored by applying a small hyperpolarizing voltage step $(-5 \mathrm{mV}, 50 \mathrm{~ms})$, and recordings that exceeded Rs $>30 \mathrm{M} \Omega$ were discarded. sEPSC recordings consisted of five sweeps/10 s-long recordings that were analyzed for amplitude and frequency of detected events. For sEPSC kinetics, all detected events per cell were used to obtain average rise (ms), decay (ms), and area $(\mathrm{pA} / \mathrm{ms})$ for all experimental groups. (2) The membrane potential was slowly shifted to $+40 \mathrm{mV}$ and 50 $\mu \mathrm{M}$ D-APV (NMDA receptor blocker) was added for at least $5 \mathrm{~min}$ to isolate AMPA-mediated responses. Eight to ten isolated AMPA responses were recorded at $+40 \mathrm{mV}$ and the membrane potential was slowly shifted to $-70 \mathrm{mV}$, where 8-10 responses were recorded. RI was calculated as the average eEPSC at $-70 \mathrm{mV}$ over the average eEPSC at $+40 \mathrm{mV}$.

Our a priori research questions were: (1) whether the treatment groups were different from the control group (Ctrl vs SA and Ctrl vs PA); (2) whether the treatment groups were different from each other (SA vs PA); and (3) do differences exist between the treatment groups if rats were tested (reexposed to the conditioning context) or not [SA (-) vs SA (+) and PA (-) vs PA (+)]. For statistical comparisons, multiple $t$ tests with corrections (BonferroniDunn method) for multiple comparisons were used to compare average saline control electrophysiological measures from PL- or IL-mPFC neuron recordings versus cocaine-treated groups. Two-tailed, unpaired $t$ tests were performed to compare sEPSC amplitude and frequency values of saline control PL- versus IL-PFC pyramidal neurons. Individual two-sample Kolmogorov-Smirnov tests were used to detect shifts between cocaine-treated groups and saline control sEPSC amplitude and interevent interval distributions. Differences of $\alpha \leq 0.05$ were considered statistically significant. All data are presented as mean \pm SEM.

\section{Drugs}

Cocaine $\mathrm{HCl}$ was gifted from the National Institutes of Health and dissolved in $0.9 \%$ saline. QX 314 chloride was purchased from Tocris. Spermine and picrotoxin were 
A

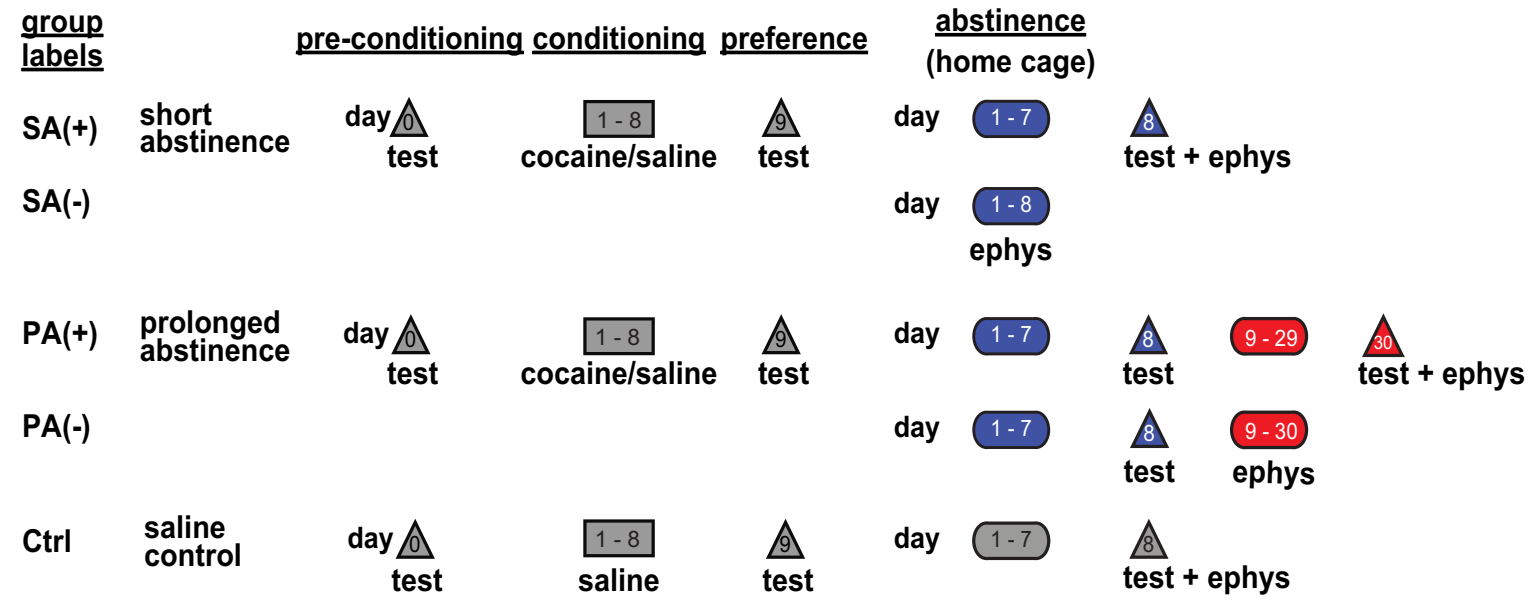
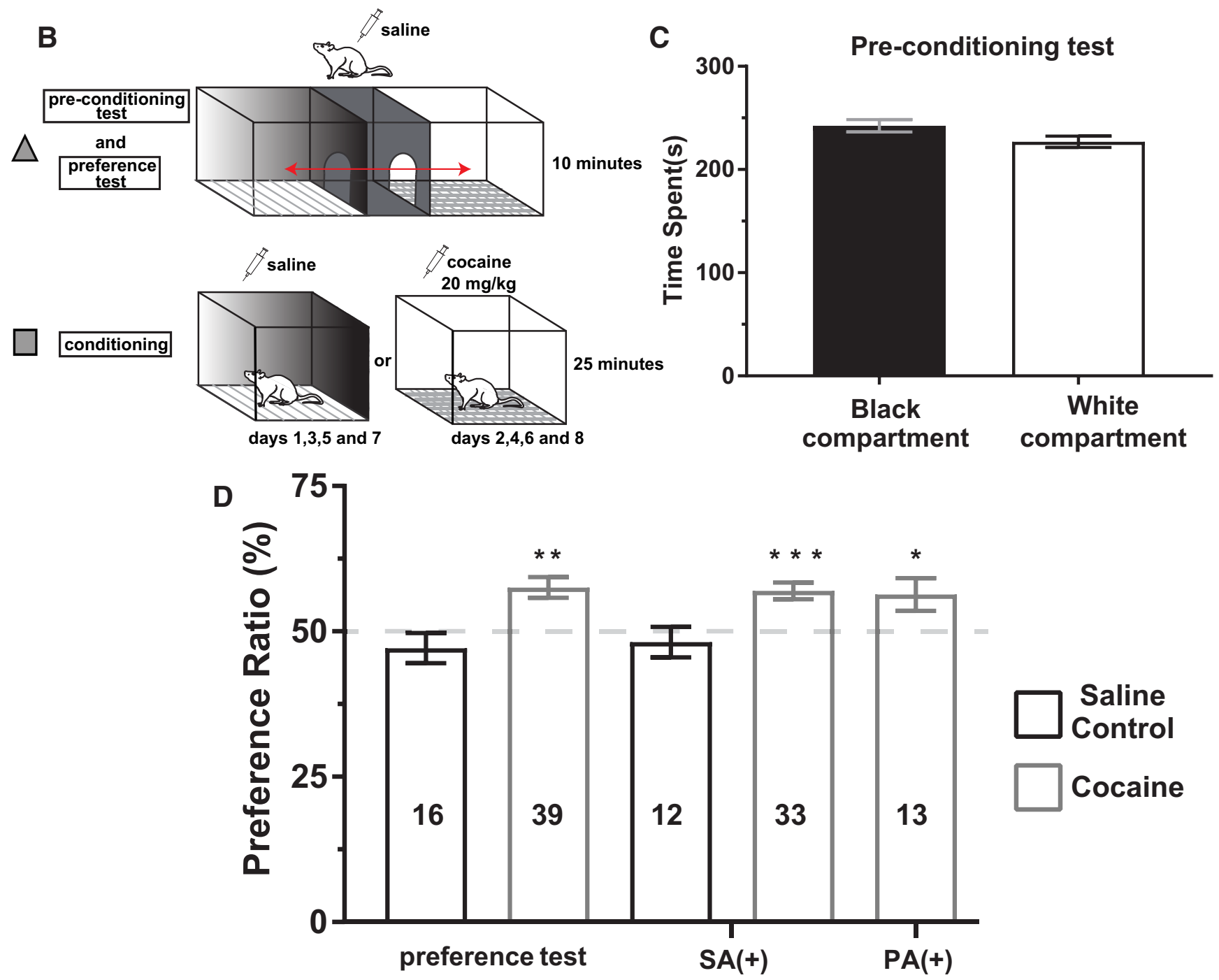

Figure 1. Cocaine-CPP is retained following SA and PA from cocaine experience. $\boldsymbol{A}$, Timeline of experiments with labels for each experimental group. $\boldsymbol{B}$, Place preference apparatus diagram with details for each stage of the cocaine-induced place conditioning procedure. $\boldsymbol{C}$, Time spent in the black and white compartments during the preconditioning (PC) test confirms the unbiased 
continued

construction of the testing apparatus. $\boldsymbol{D}$, Preference ratio [(time in cocaine paired compartment/time spent in both compartments) $\times$ 100]. Saline-treated (black border) rats and cocaine-conditioned (gray border) rats tested $24 \mathrm{~h}$ after the last day of conditioning, after $8 \mathrm{~d}$ of abstinence $[\mathrm{SA}(+)]$ and after $30 \mathrm{~d}$ of abstinence $[\mathrm{PA}(+)] ; * p=0.0436, * * p=0.0002, * * * p<0.0001$ indicate significantly above $50 \%$.

purchased from Sigma-Aldrich. D-APV was purchased from Abcam. All drugs used in the electrophysiological recordings were dissolved in recording ACSF and bath applied except for QX 314 and spermine, which were dissolved into internal ACSF and stocks were further diluted in the internal solution the day of recording.

\section{Results}

We used the cocaine-CPP paradigm to assess the cocaine-associated contextual cue effects on glutamatergic synaptic transmission in mPFC. Whole-cell voltage clamp recordings were performed from layer $5 / 6$ pyramidal neurons of PL- or IL-mPFC in brain slices of adult male rats (Fig. 1A,B).

\section{Behavior: cocaine-induced CPP}

During the PC test, rats spent similar amounts of time in the black and white compartments confirming the unbiased construction of the testing apparatus (Fig. 1C). Saline control rats did not show a conditioned response, given that preference ratios did not differ from chance performance on the initial preference test $\left(t_{(15)}=1.103, p\right.$ $>0.05)$ or the SA test $\left(t_{(11)}=0.71, p>0.05\right.$; Fig. $\left.1 D\right)$. Rats conditioned with $20 \mathrm{mg} / \mathrm{kg}$ i.p. cocaine displayed a preference for the cocaine paired compartment as indicated by a preference ratio greater than chance performance on the initial test for place conditioning $\left(t_{(38)}=4.194, p=\right.$ $0.0002)$ the SA test $\left[S A(+), t_{(32)}=4.835, p<0.0001\right]$ and the PA test $\left[\mathrm{PA}(+), t_{(12)}=2.255, p=0.0436\right.$; Fig. $\left.1 D\right]$. In summary, these results suggest that in the course of abstinence, when cocaine-treated rats are reexposed to the cocaine-associated context under drug free conditions, the difference in preference ratios from the respective saline control group becomes higher with longer abstinence. These results could be interpreted as a disruption of the rewarding memory of the initial cocaine experience, leading to a slight decrease in cocaine seeking behavior.

\section{Electrophysiology: sEPSCs}

We measured frequency and amplitude of sEPSCs in our experimental and control groups to investigate the basal differences between PL- and IL-mPFC deep layer $5 / 6$ pyramidal neurons and to assess the changes in synaptic glutamate transmission after two different abstinence time points (SA, $8 \mathrm{~d}$ of abstinence; and PA, $30 \mathrm{~d}$ of abstinence) from cocaine-induced CPP.

When comparing amplitude and frequency of sEPSCs between PL- and IL-mPFC in saline animals, we found no statistical differences in the amplitude of spontaneous events but we found that IL-mPFC neurons exhibit a significantly lower frequency of sEPSCs than the PLmPFC (Ctrl: $t_{(11)}=4.676, p=0.0007$; Fig. $\left.2 A, B\right)$.

\section{Cocaine-induced CPP after SA or PA: sEPSCs amplitude}

In the PL-mPFC, we found a significant reduction in the amplitude of SEPSCs relative to Ctrl levels exclusively in neurons from $S A(-)$ rats that were not reexposed to the cocaine-associated context [SA(-): $t_{(10)}=2.914, p=$ 0.031 ; Fig. $2 D$, inset]. Similarly, in the IL-mPFC, we observed a reduction in the amplitude of $S E P S C s$ only in $\mathrm{SA}(-)$ rats $\left(t_{(9)}=3.086, p=0.026\right.$; Fig. $2 G$, inset).

\section{Cocaine-induced CPP after SA or PA: sEPSCs frequency}

Our results showed that PL-mPFC deep layer pyramidal neurons exhibit a significant reduction in the frequency of sEPSCs in all cocaine-CPP groups relative to saline values, except for the PA(-) group: [SA(-): $t_{(10)}=6.498, p=$ 0.0001; $(\mathrm{SA}+): t_{(16)}=3.618, p=0.0046 ; \mathrm{PA}(+): t_{(12)}=$ 4.815. $p=0.0008$; Fig. $2 E$, inset]. In contrast to the findings in the PL-mPFC, cocaine-induced CPP followed by abstinence did not elicit significant changes in the frequency of sEPSCs in IL-mPFC neurons (Fig. $2 \mathrm{H}$, inset).

Our findings suggest that under basal conditions, pyramidal neurons located in deep layers of the PL-mPFC receive higher levels of glutamate input compared to ILmPFC neurons. Moreover, cocaine-CPP followed by abstinence elicits different cortical adaptations in glutamate synaptic transmission in MPFC neurons after short and long abstinence periods. SA elicited decreases in the amplitude of glutamate-mediated currents, suggesting a postsynaptic decrease in receptor levels in PL- and ILmPFC neurons in rats that were not reexposed to the cocaine-associated context (were not tested for CPP). In contrast, we found a decrease in the frequency of excitatory synaptic inputs only in PL-mPFC neurons. This decrease was independent of reexposure or deprivation of the cocaine-associated context and suggests a maintained pharmacological mechanism perhaps originating from the repeated cocaine exposure.

\section{sEPSC kinetics}

To further address cocaine-CPP changes in spontaneous glutamate transmission, we used the average sEPSC event kinetics as an indirect measure of glutamate receptor dynamics (Hollmann et al., 1989; Keller et al., 1991; Tomita, 2010; Traynelis et al., 2010). Analysis of individual events from sEPSC recordings in PL-mPFC layer 5/6 pyramidal neurons revealed a significant decrease in the area under the curve in SEPSC events from SA(-) PLmPFC neurons $\left(t_{(10)}=2.942, p=0.029\right)$ Fig. $3 D$. Consistent with the difference between MPFC subregions, in the IL-mPFC we found no difference in the rise time and decay time for the average of all detected sEPSC events, Fig. 3. 
A

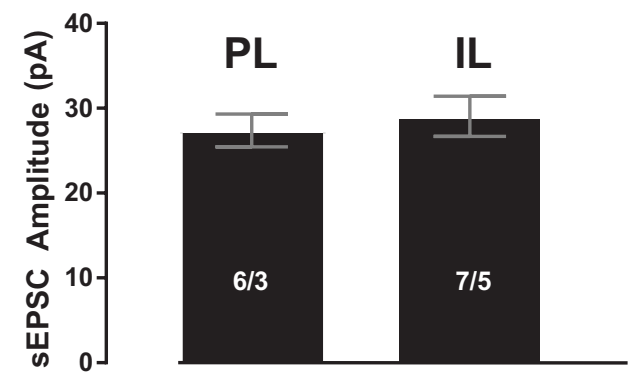

C

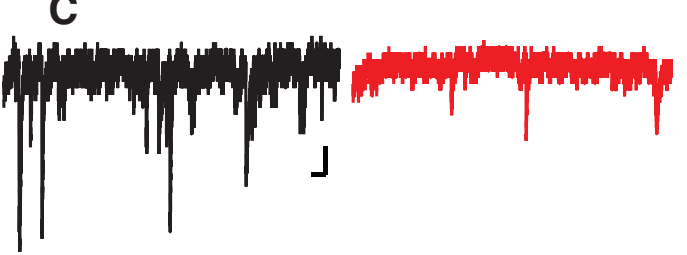

D

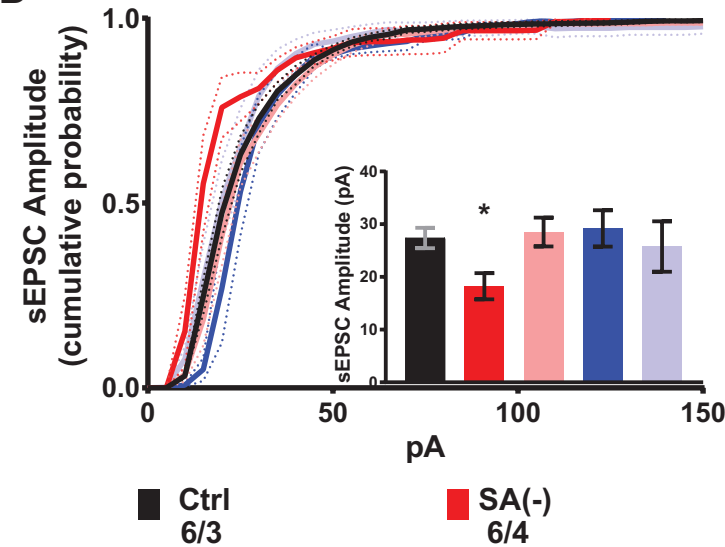

B

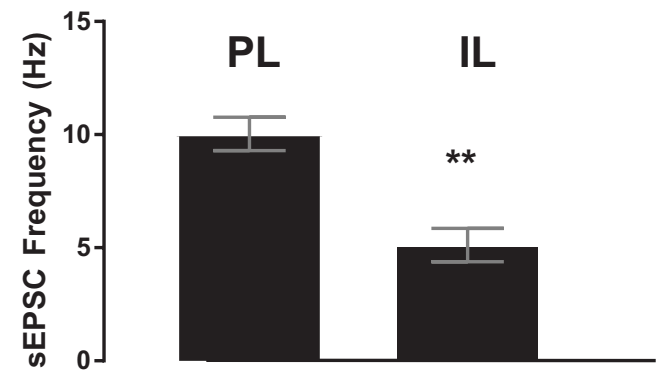

F

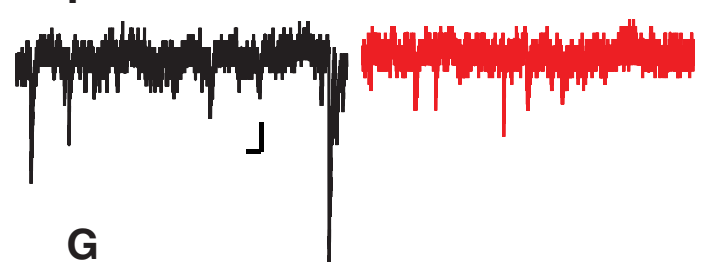

G
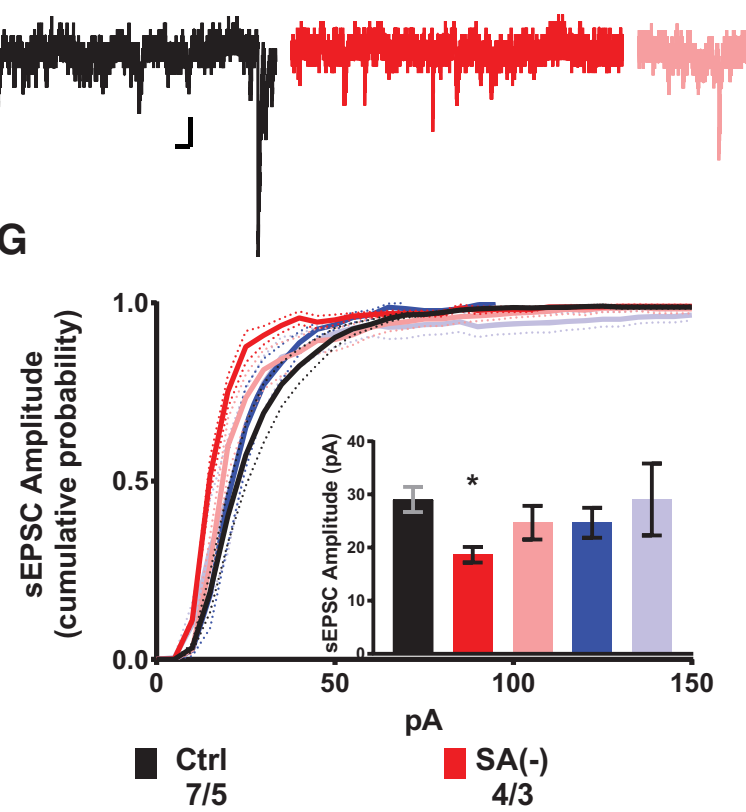

SA(+)

$12 / 6$
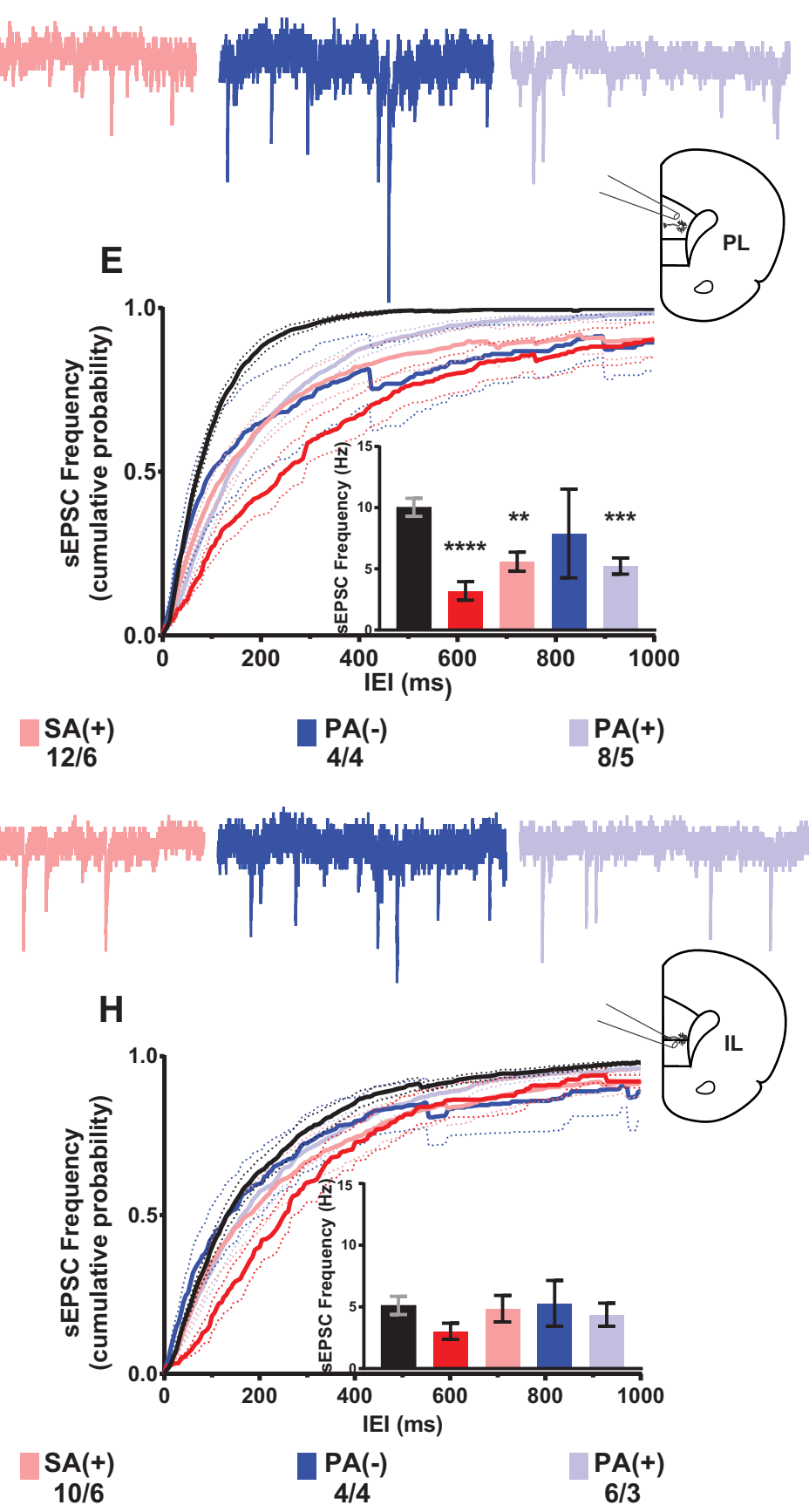

Figure 2. Cocaine-associated context experience-dependent alterations in sEPSC properties in deep layer $5 / 6$ pyramidal neurons of $\mathrm{PL}$-and IL-mPFC. $\boldsymbol{A}, \boldsymbol{B}$, Comparison of sEPSC amplitude and frequency (mean \pm SEM pA and Hz, respectively) from PL-mPFC versus IL-mPFC deep layer 5/6 pyramidal neurons in saline-treated control rats. $\boldsymbol{C}$, Representative traces of sEPSC recordings from 
continued

PL-mPFC pyramidal neurons for each experimental group with a diagram for recording location on brain slice. $\boldsymbol{D}$, $\boldsymbol{E}$, Comparison of sEPSC amplitude and frequency cumulative probability distributions from PL-mPFC pyramidal neurons for each experimental group. Insets show average data for sEPSC amplitude and frequency (mean \pm SEM pA and Hz, respectively). $\boldsymbol{F}$, Representative traces of sEPSC recordings from IL-mPFC pyramidal neurons for each experimental group with diagram for recording location on brain slice. $\mathbf{G}, \boldsymbol{H}$, Comparison of sEPSC amplitude and frequency cumulative probability distributions from PL-mPFC pyramidal neurons for each experimental group. Insets show average data for sEPSC amplitude and frequency (mean \pm SEM pA and Hz, respectively). Statistics on bar graphs represent adjusted $p$ values calculated from multiple $t$ tests against saline control measurements corrected for multiple comparisons (Bonferroni-Dunn method). Cumulative probability distributions were tested individually against saline control distributions for each sEPSC measurement; $* p<0.05$, $* * p<0.005$, $* * * p<0.001$, $* * * * p<0.0005$. Numbers represent cells/rats. Scale bars: $100 \mathrm{~ms}$ (horizontal), $10 \mathrm{pA}$ (vertical).

In summary, our results showed that the activation and inactivation rate of sEPSCs are, for the most part, unaltered in PL- and IL-mPFC neurons of saline and cocainetreated rats. The significant decrease in area under the curve observed in 8-d abstinent rats that were not reexposed to the cocaine-conditioned context [SA(-)] follows the decrease in sEPSC amplitude and is similarly reversed on context reexposure. Since changes in sEPSC area under the curve are thought to represent the net charge transfer during an ionotropic glutamate receptor-mediated event, this result suggests that SA after cocaine conditioning decreases the glutamatergic excitatory strength in PL-mPFC deep layer 5/6 pyramidal neurons (Keller et al., 1991).

\section{RI}

Previous studies have shown that protracted abstinence increases $\mathrm{Ca}^{2+}$-permeable AMPARs (CP-ARs) in the NAc of cocaine self-administering rats (Conrad et al., 2008; McCutcheon et al., 2011) and alterations in AMPA receptor $\mathrm{Ca}^{2+}$ permeability has been shown to increase neuronal excitability (Li et al., 2012). To explore if similar neuroadaptations occur in PL- and/or IL-mPFC, we assessed the $\mathrm{RI}$ in our cocaine-CPP rats as an indirect measure of CP-AR levels, where an increase in RI suggests a higher contribution of CP-ARs and a decrease in $\mathrm{Rl}$ suggests less contribution of CP-ARs. Our results show a significant increase in the $\mathrm{RI}$ in PL-mPFC from $\mathrm{PA}(-)$ neurons compared to saline control values $\left(t_{(7)}=\right.$ $0.0117, p=0.0207$; Fig. 4B). This data suggests that only protracted abstinence (30 d after the initial CPP test) from cocaine treatment produces an increase in $\mathrm{RI}$, similar to what has been previously reported in NAc medium spiny neurons (MSNs) from long-access cocaine self-administering rats. When $\mathrm{Rl}$ was assessed in IL-mPFC neurons, there were no significant differences from saline controls in any of the cocaine-treated groups (Fig. 4D).

In summary, our results showed for the first time that layer 5/6 pyramidal neurons from the PL- and IL-mPFC are intrinsically different in their excitatory synaptic activity (see differences in basal sEPSC frequency). Furthermore, we showed that cocaine-CPP induces differential effects between PL-mPFC and IL-mPFC neurons that are dependent on the length of abstinence. Experiments showed general mPFC decreases in excitatory synaptic inputs to pyramidal cells following SA ( $8 \mathrm{~d}$ after the initial CPP test) and changes in glutamate receptor dynamics after PA (30 d after the initial CPP test). Moreover, after a period of PA, we found a PL-specific increase in the contribution of CP-ARs in response to electrical stimulation of glutamate terminals innervating layer $5 / 6$ pyramidal neurons.

\section{Discussion}

Our results are the first to show that deep layer pyramidal neurons from PL- and IL-mPFC differ in the frequency of their excitatory synaptic inputs, with the PLmPFC exhibiting higher frequency of excitatory inputs than the IL-mPFC. Furthermore, our results showed that cocaine conditioning followed by abstinence elicits differential effects on PL- and IL-mPFC pyramidal neurons and that these glutamatergic changes could represent synaptic alterations that mediate the retention of the cocaineassociated rewarding memory.

\section{Presynaptic markers}

It has been proposed that changes in frequency of sEPSCs reflect modifications at the presynaptic level (Engelman and MacDermott, 2004; Costa et al., 2017). Interestingly, our results showed that PL-mPFC neurons exhibit higher basal frequency of sEPSCs compared to IL-mPFC neurons. This reduced basal frequency of synaptic glutamate currents in IL-mPFC neurons may be a phenotype of this distinct neuronal population arising from differences in dendritic cytoarchitecture and glutamate afferents innervating this region (Van Eden and Uylings, 1985; Hoover and Vertes, 2007). In addition, the reduced basal frequency of sEPSCs in IL-mPFC neurons could preclude any further reduction in this neuronal population, thus supporting the lack of effects observed following cocaine experience, abstinence and cocainecontext reexposure. It is tempting to speculate that higher excitatory drive onto PL-mPFC neurons plays a role in the retention of the rewarding effects of cocaine after abstinence.

We show that cocaine-induced CPP elicits a significant reduction in the frequency of sEPSCs in PL-mPFC in all groups except the PA(-) group. In contrast, we did not find changes in SEPSC frequency in IL-mPFC neurons. Based on these results, we propose that abstinence from cocaine experience selectively alters excitatory inputs to the PL-mPFC. A recent study showed that cocaine-CPP produced an increase in sEPSC frequency in PL-mPFC neurons (Otis and Mueller, 2017). The discrepancy with our results can be explained by the length between the last conditioning session and the time of recording; their re- 
A
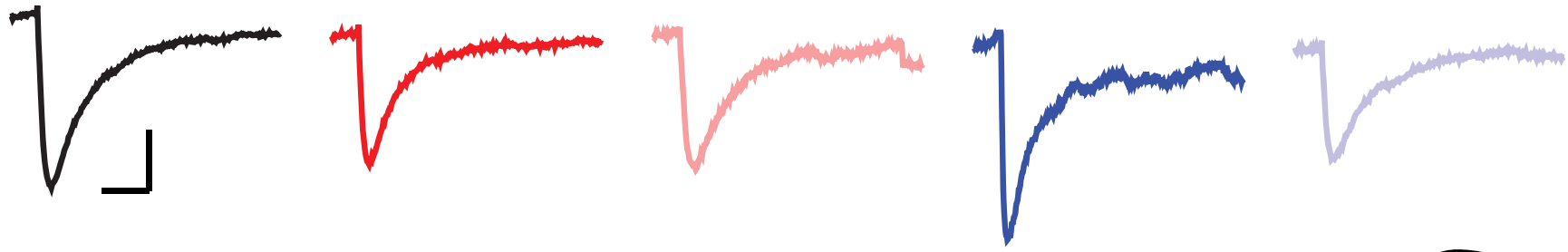

B

C

D
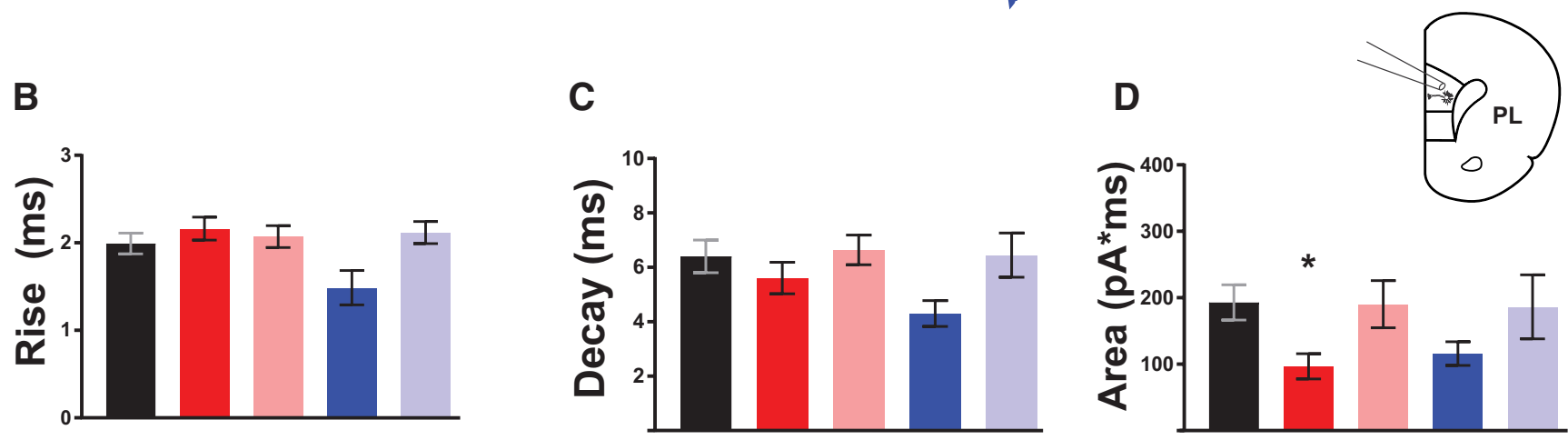

Ctrl

SA(-)

6/4

$\mathrm{SA}(+)$

$12 / 6$

PA(-)

4/4

$\mathrm{PA}(+)$

$8 / 5$

E
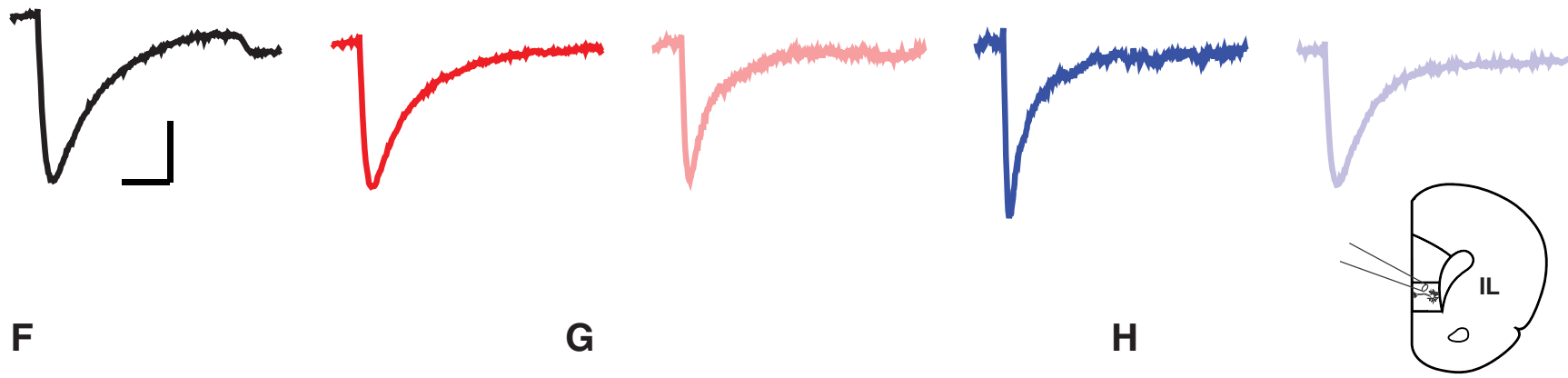

F

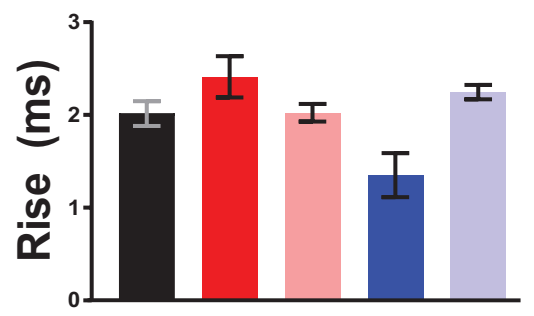

G

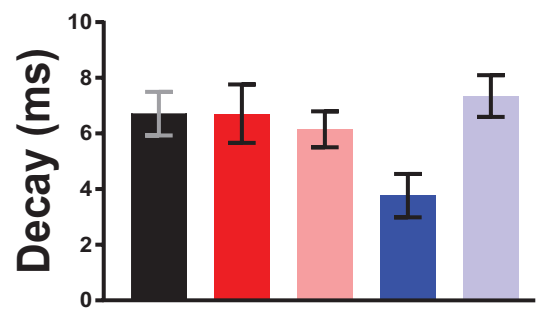

SA(-)

$4 / 3$
SA(+)

10/6
$\mathbf{H}$

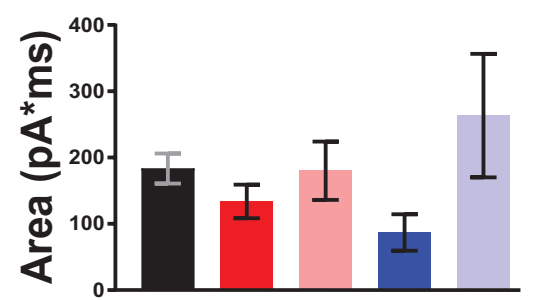

PA(-)

4/4
$\mathrm{PA}(+)$

$6 / 3$

Figure 3. Cocaine-associated context experience-dependent alterations in the kinetics of sEPSCs in deep layer $5 / 6$ pyramidal neurons of PL- and IL-mPFC. A, Average traces from single events in representative sEPSC recordings from PL-mPFC pyramidal neurons for each experimental group with diagram for recording location on brain slice. $\boldsymbol{B}, \boldsymbol{F}$, Average rise time from all events detected in SEPSC recordings for PL- and IL-mPFC pyramidal neurons respectively (mean \pm SEM ms). $\boldsymbol{C}, \boldsymbol{G}$, Average decay time from all events detected in sEPSC recordings for PL- and IL-mPFC pyramidal neurons respectively (mean \pm SEM $\mathrm{ms}$ ). $\boldsymbol{D}, \boldsymbol{H}$, Average area under the curve from all events detected in SEPSC recordings for PL- and IL-mPFC pyramidal neurons respectively (mean \pm SEM $\mathrm{pA} / \mathrm{ms})$. $\boldsymbol{E}$, Average traces from single events in representative sEPSC recordings from PL-mPFC pyramidal neurons for each 
continued

experimental group with diagram for recording location on brain slice. Statistics on bar graphs represent adjusted $p$ values calculated from multiple $t$ tests against saline control measurements corrected for multiple comparisons (Bonferroni-Dunn method); $p<0.05$. Numbers represent cells/rats. Scale bars: $10 \mathrm{~ms}$ (horizontal), $10 \mathrm{pA}$ (vertical).

cordings were performed $4 \mathrm{~d}$ after the last conditioning session and we recorded from rats after at least $8 \mathrm{~d}$ of abstinence. Work from Hoover and Vertes (2007) show distinct patterns of excitatory afferents from multiple limbic, thalamic and cortical nuclei innervating PL- and ILmPFC neurons, and thus future studies should selectively target each excitatory input to investigate which inputs are relevant to the induction of these specific changes in glutamate transmission after abstinence from cocaineCPP (Hoover and Vertes, 2007) additional experiments should focus on elucidating the origin of our reported synaptic changes by implementing a combination of electrophysiological assays that target presynaptic analysis with postsynaptic measures(Graziane and Dong, 2016).

\section{Postsynaptic markers}

Changes in amplitude of sEPSCs are generally associated with differences in the levels of postsynaptic receptors and/or changes in the dynamics of the receptors (Engelman and MacDermott, 2004; Costa et al., 2017). A comparison of the average SEPSC amplitude found that cocaine-CPP elicited only a reduction in the amplitude of sEPSCs in PL- and IL-mPFC pyramidal cells after SA without reexposure to the cocaine-associated context [SA(-)], but this decrease was not maintained long-term. A recent study (Otis and Mueller, 2017) showed an increase in sEPSC amplitude in PL-mPFC neurons following cocaine-CPP. The difference with our results could be explained by a memory reconsolidation mechanism that was not activated in our study since our rats remained in the home cage before the recordings. The presence of the reduction in amplitude of sEPSCs in both MPFC subregions suggests a common short-term neuroadaptation by which cocaine experience, in combination with deprivation from the cocaine-associated context, decreases the levels of postsynaptic glutamate receptors. After SA, retrieval of the cocaine-context association memory could be enough to disrupt this adaptation. Moreover, because our rats were tested at multiple intervals for the retention of cocaine-CPP, it is possible that at longer periods of abstinence, this modification is either not necessary for the expression of cocaine-induced CPP or has been disrupted by the emergence of an extinction memory.

Changes in the kinetics of SEPSC events can be indicative of alterations in receptor subunit composition and their interactions with auxiliary subunits as well as alternative RNA splicing and post-translational modifications (Dingledine et al., 1999; Tomita, 2010; Granger et al., 2011; Stincic and Frerking, 2015). Using the CPP protocol with cocaine exposure followed by different periods of abstinence, we found that only PL-mPFC neurons exhibited a decrease in the area under the curve in the SA (-) group. Given the low contribution of NMDA receptors at $-70 \mathrm{mV}$, we interpreted these changes in SEPSC area as alterations in AMPA glutamate receptor dynamics and a putative by-product of the combination of the factors mentioned above. Moreover, these changes appear to be dependent on SA and deprivation from the cocaineconditioned context.

It is important to state that a portion of our experimental groups have small samples sizes; therefore, in future studies, we will attempt to expand these experiments to parse out any underpowered effects that might have gone undetected.

\section{RI}

Previous reports have shown that long-access cocaine SA followed by PA elicits an increase in the number of calcium permeable AMPA receptors (CP-ARs) in NAc MSNs (Conrad et al., 2008), thus providing a synaptic marker of the incubation of cocaine craving in this brain region. Based on these studies and the influence that PFC projection neurons have within the drug-seeking circuit, we assessed changes in $\mathrm{Rl}$ (as a relative measure of CP-AR's contribution) in our different experimental groups. We found that cocaine-CPP followed by abstinence elicited a significant increase in RI only in the PL-mPFC $[P A(-)]$. This result suggests that longer periods of withdrawal from the cocaine experience are required to produce an increase in RI, similar to what has been previously reported in NAc MSNs from long-access cocaine selfadministering rats (Conrad et al., 2008). An increase in surface level expression of CP-ARs, with enhanced single channel conductance, could increase the excitability of mPFC pyramidal neurons in similar fashion to the effects of GluR2-lacking AMPARs reported in PVN neurons in spontaneous hypertensive rats (Li et al., 2012). Our results suggest that PA alters the activity of PL-mPFC neurons via an unknown mechanism leading to a compensatory increase in AMPA receptor RI that can potentially drive the retention of cocaine-induced CPP.

Silent synapses, synapses devoid of AMPA receptors, were initially reported in hippocampal CA1 neurons in studies demonstrating that their "unsilencing" required the insertion of AMPA receptors on induction of LTP (Isaac et al., 1995; Liao et al., 1995). Huang and colleagues established an association between silent synapses and in vivo cocaine experience, where the salience attributed to the drug experience is sufficient to generate de novo silent synapses (Huang et al., 2009). Cocaineinduced silent synapse formation has been shown to generate a permissive state for remodeling of the NAc neurocircuits in several cocaine-related behaviors including CPP, locomotor sensitization and cue-induced reinstatement of cocaine self-administration (Brown et al., 2011; Lee et al., 2013; Ma et al., 2014; Dong, 2015; Shukla et al., 2017). Particularly relevant to our study is the evidence of silent synapse-based circuit remodeling in the mPFC-NAc pathway during cocaine craving, showing that maturation of the IL-mPFC-NAc pathway requires the 


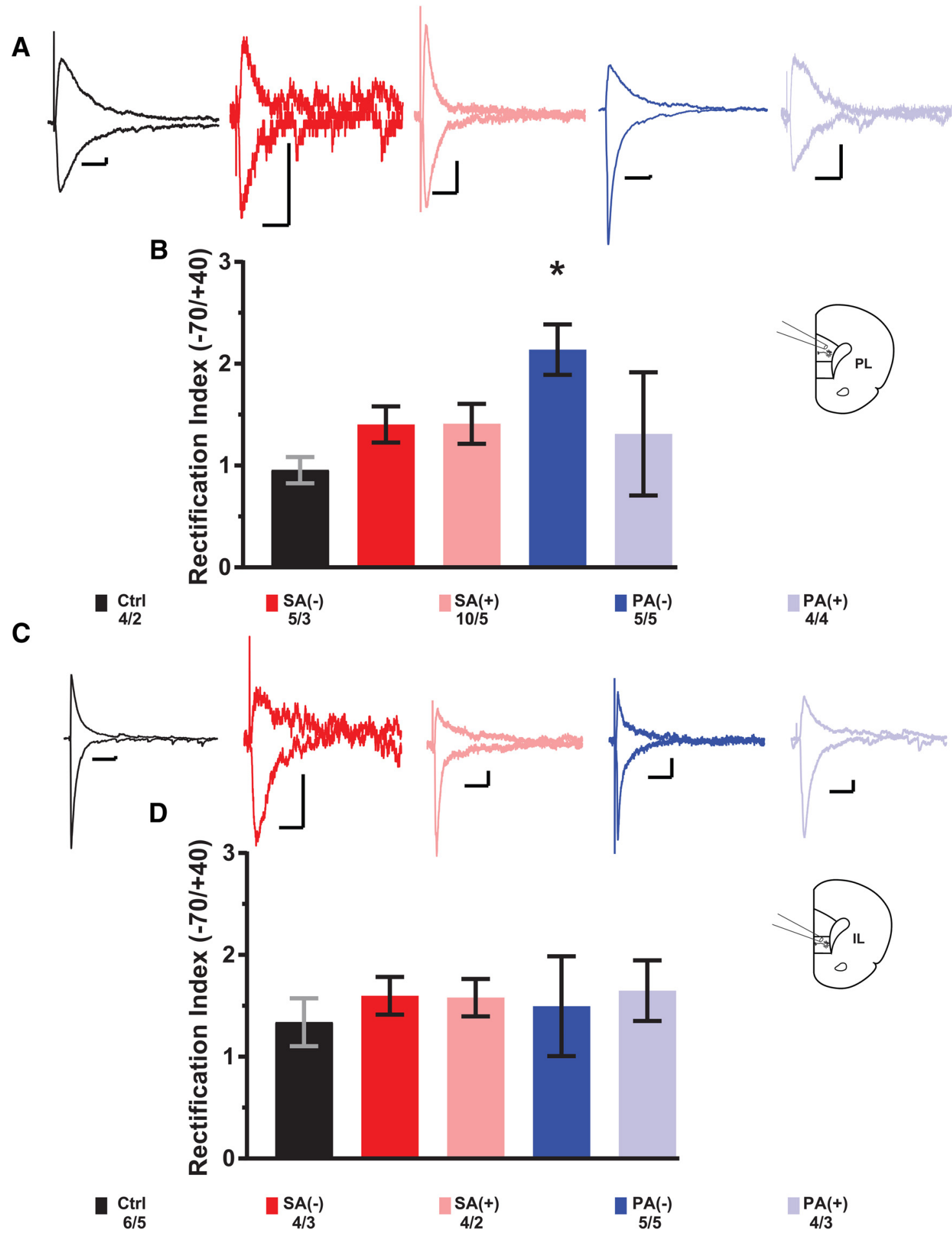

Figure 4. Cocaine-associated context experience-dependent alterations in the RI in deep layer $5 / 6$ pyramidal neurons of $\mathrm{PL}$ and IL-mPFC. A, B, Representative traces from single evoked EPSC recordings from PL- and IL-mPFC pyramidal neurons, respectively, at $+40 \mathrm{mV}$ (outward) and $-70 \mathrm{mV}$ (inward) for each experimental group with diagram for recording location on brain slice. $\boldsymbol{B}, \boldsymbol{D}$, Average RI values calculated as evoked EPSC amplitude at $-70 \mathrm{mV}$ over $+40 \mathrm{mV}$ membrane potentials for PL- and IL-mPFC pyramidal neurons respectively. Statistics on bar graphs represent adjusted $p$ values calculated from multiple $t$ tests against saline control measurements corrected for multiple comparisons (Bonferroni-Dunn method); $p<0.05$. Numbers represent cells/rats. Scale bars: $100 \mathrm{~ms}$ (horizontal), $10 \mathrm{pA}$ (vertical). 
A

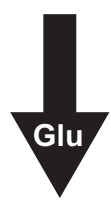

basal difference in sEPSC frequency
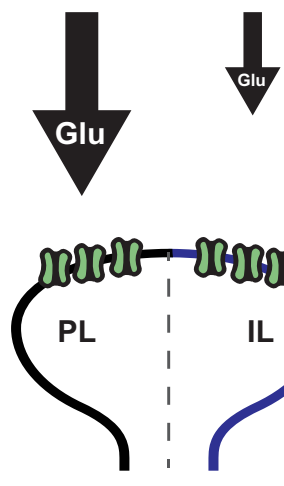

glutamate-gated

ionotropic receptor

(AMPA)

glutamate-gated

ionotropic receptor

(AMPA) *with altered

kinetics

medial PFC

deep layer $5 / 6$

pyramidal neurons

\section{Control}

(Ctrl)

B

PL

decrease in SEPSC frequency and

amplitude

decrease in area under the curve
IL

decrease in SEPSC amplitude and no change in frequency

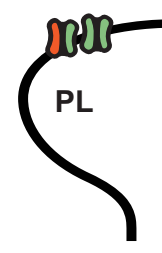

SA(-)

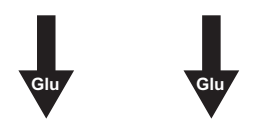

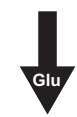

\section{Short Abstinence}

(SA)

C

PL

increase in RI

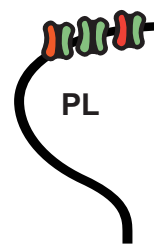

PL | IL

reversal of SEPSC decrease in amplitude with no change in frequency

$$
\text { PA(-) }
$$
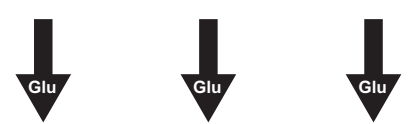

IL

SA(+)

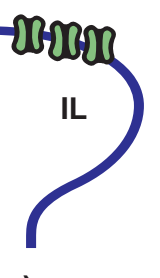


recruitment of CP-AMPARs and that maturation of the PL-mPFC-NAc pathway requires insertion of non-CPAMPARs. Reversing excitatory synapse remodeling with optogenetic stimulation of the IL-mPFC to NAc shell and the PL-mPFC to NAc core pathways can potentiate or inhibit incubation of cocaine craving, respectively (Ma et al., 2014). It remains to be studied whether similar forms of circuit remodeling occur at the level of mPFC afferents. The following questions remains to be answered: do cocaine-context associations require the generation of de novo silent synapses in deep layer mPFC pyramidal neurons, and does this PL- vs IL-mPFC dichotomy prevail upstream from the NAc?

\section{Conclusion}

PL- and IL-mPFC deep layer 5/6 pyramidal neurons differ in their excitatory inputs, with PL-mPFC exhibiting higher basal frequency of sEPSCs, which suggests an important role of this subcortical region for the neuroplasticity of addiction. Cocaine-CPP elicits different neuroadaptations in mPFC neurons depending on the length of abstinence, and the specific changes are detailed in the summary diagram (Fig. 5). General adaptations appeared after SA (8 d after the initial CPP test) in both PL- and IL-mPFC neurons, suggesting the maintenance of the pharmacological effects of cocaine, whereas alterations in frequency of glutamate inputs after SA were specific to PL-mPFC neurons. In both cases, these effects were only present in rats deprived from context reexposure and were not present after PA (30 d after the initial CPP test). PA produces PL-specific changes in CP-AMPARs, suggesting a time sensitivity to the effects of cocaine-induced $\mathrm{CPP}$ in mPFC synaptic glutamate transmission.

\section{References}

Briand LA, Flagel SB, Garcia-Fuster MJ, Watson SJ, Akil H, Sarter M, Robinson TE (2008) Persistent alterations in cognitive function and prefrontal dopamine D2 receptors following extended, but not limited, access to self-administered cocaine. Neuropsychopharmacology 33:2969-2980. CrossRef

Brown TE, Lee BR, Mu P, Ferguson D, Dietz D, Ohnishi YN, Lin Y, Suska A, Ishikawa M, Huang $Y H$, Shen $H$, Kalivas PW, Sorg BA, Zukin RS, Nestler EJ, Dong Y, Schlüter OM (2011) A silent synapse-based mechanism for cocaine-induced locomotor sensitization. J Neurosci 31:8163-8174. CrossRef Medline

Conrad KL, Tseng KY, Uejima JL, Reimers JM, Heng LJ, Shaham Y, Marinelli M, Wolf ME (2008) Formation of accumbens GluR2lacking AMPA receptors mediates incubation of cocaine craving. Nature 454:118-121. CrossRef Medline

Costa RP, Mizusaki BE, Sjöström PJ, van Rossum MC (2017) Functional consequences of pre- and postsynaptic expression of synaptic plasticity. Philos Trans R Soc Lond B Biol Sci 372:CrossRef

Coutlee CG, Huettel SA (2012) The functional neuroanatomy of decision making: prefrontal control of thought and action. Brain Res 1428:3-12. CrossRef Medline

Dingledine R, Borges K, Bowie D, Traynelis SF (1999) The glutamate receptor ion channels. Pharmacol Rev 51:7-61. Medline

Dong $Y(2015)$ Silent synapse-based circuitry remodeling in drug addiction. Int J Neuropsychopharmacol 19.

Engelman HS, MacDermott AB (2004) Presynaptic ionotropic receptors and control of transmitter release. Nat Rev Neurosci 5:135145. CrossRef Medline

George O, Mandyam CD, Wee S, Koob GF (2008) Extended access to cocaine self-administration produces long-lasting prefrontal cortex-dependent working memory impairments. Neuropsychopharmacology 33:2474-2482. CrossRef

Ghasemzadeh MB, Vasudevan P, Giles C, Purgianto A, Seubert C, Mantsch JR (2011) Glutamatergic plasticity in medial prefrontal cortex and ventral tegmental area following extended-access cocaine self-administration. Brain Res 1413:60-71. CrossRef Medline

Gipson CD, Kupchik YM, Kalivas PW (2014) Rapid, transient synaptic plasticity in addiction. Neuropharmacology 76 [Pt B]:276-286. CrossRef Medline

Goldstein RZ, Volkow ND (2011) Dysfunction of the prefrontal cortex in addiction: neuroimaging findings and clinical implications. Nat Rev Neurosci 12:652-669. CrossRef Medline

Granger AJ, Gray JA, Lu W, Nicoll RA (2011) Genetic analysis of neuronal ionotropic glutamate receptor subunits. J Physiol 589: 4095-4101. CrossRef Medline

Graziane N, Dong Y (2016) Pre vs. Post synaptic Effect. In: Electrophysiological analysis of synaptic Transmission, pp 175-186. New York, NY: Springer New York.

Heidbreder CA, Groenewegen HJ (2003) The medial prefrontal cortex in the rat: evidence for a dorso-ventral distinction based upon functional and anatomical characteristics. Neurosci Biobehav Rev 27:555-579. Medline

Hollmann M, O'Shea-Greenfield A, Rogers SW, Heinemann S (1989) Cloning by functional expression of a member of the glutamate receptor family. Nature 342:643-648. CrossRef Medline

Hoover WB, Vertes RP (2007) Anatomical analysis of afferent projections to the medial prefrontal cortex in the rat. Brain Struct Funct 212:149-179. CrossRef Medline

Huang YH, Lin Y, Mu P, Lee BR, Brown TE, Wayman G, Marie H, Liu W, Yan Z, Sorg BA, Schlüter OM, Zukin RS, Dong Y (2009) In vivo cocaine experience generates silent synapses. Neuron 63:40-47. CrossRef Medline

Isaac JT, Nicoll RA, Malenka RC (1995) Evidence for silent synapses: implications for the expression of LTP. Neuron 15:427-434. Medline

Keller BU, Konnerth A, Yaari Y (1991) Patch clamp analysis of excitatory synaptic currents in granule cells of rat hippocampus. $J$ Physiol 435:275-293. Medline

Kim S, Lee D (2011) Prefrontal cortex and impulsive decision making. Biol Psychiatry 69:1140-1146. CrossRef Medline

LaLumiere RT, Smith KC, Kalivas PW (2012) Neural circuit competition in cocaine-seeking: roles of the infralimbic cortex and nucleus accumbens shell. Eur J Neurosci 35:614-622. CrossRef Medline

Lee BR, Ma YY, Huang YH, Wang X, Otaka M, Ishikawa M, Neumann PA, Graziane NM, Brown TE, Suska A, Guo C, Lobo MK, Sesack SR, Wolf ME, Nestler EJ, Shaham Y, Schlüter OM, Dong Y (2013) Maturation of silent synapses in amygdala-accumbens projection contributes to incubation of cocaine craving. Nat Neurosci 16: 1644-1651. CrossRef Medline

Li DP, Byan HS, Pan HL (2012) Switch to glutamate receptor 2-lacking AMPA receptors increases neuronal excitability in hypothalamus and sympathetic drive in hypertension. J Neurosci 32: 372-380. CrossRef Medline

Liao D, Hessler NA, Malinow R (1995) Activation of postsynaptically silent synapses during pairing-induced LTP in CA1 region of hippocampal slice. Nature 375:400-404. CrossRef Medline

Ma YY, Lee BR, Wang X, Guo C, Liu L, Cui R, Lan Y, Balcita-Pedicino JJ, Wolf ME, Sesack SR, Shaham Y, Schlüter OM, Huang YH, Dong $Y$ (2014) Bidirectional modulation of incubation of cocaine craving by silent synapse-based remodeling of prefrontal cortex to accumbens projections. Neuron 83:1453-1467. CrossRef Medline

Mansouri FA, Tanaka K, Buckley MJ (2009) Conflict-induced behavioural adjustment: a clue to the executive functions of the prefrontal cortex. Nat Rev Neurosci 10:141-152. CrossRef Medline

McCutcheon JE, Wang X, Tseng KY, Wolf ME, Marinelli M (2011) Calcium-permeable AMPA receptors are present in nucleus accumbens synapses after prolonged withdrawal from cocaine selfadministration but not experimenter-administered cocaine. J Neurosci 31:5737-5743. CrossRef 
McFarland K, Lapish CC, Kalivas PW (2003) Prefrontal glutamate release into the core of the nucleus accumbens mediates cocaineinduced reinstatement of drug-seeking behavior. J Neurosci 23: 3531-3537. Medline

McGlinchey EM, James MH, Mahler SV, Pantazis C, Aston-Jones G (2016) Prelimbic to accumbens core pathway is recruited in a dopamine-dependent manner to drive cued reinstatement of cocaine seeking. J Neurosci 36:8700-8711. CrossRef Medline

McLaughlin J, See RE (2003) Selective inactivation of the dorsomedial prefrontal cortex and the basolateral amygdala attenuates conditioned-cued reinstatement of extinguished cocaine-seeking behavior in rats. Psychopharmacology (Berl) 168:57-65. CrossRef Medline

Mueller D, Stewart J (2000) Cocaine-induced conditioned place preference: reinstatement by priming injections of cocaine after extinction. Behav Brain Res 115:39-47. Medline

Otis JM, Mueller D (2017) Reversal of cocaine-associated synaptic plasticity in medial prefrontal cortex parallels elimination of memory retrieval. Neuropsychopharmacology 42:2000-2010.

Peters J, LaLumiere RT, Kalivas PW (2008) Infralimbic prefrontal cortex is responsible for inhibiting cocaine seeking in extinguished rats. J Neurosci 28:6046-6053. CrossRef Medline

Reichel CM, Bevins RA (2008) Competition between the conditioned rewarding effects of cocaine and novelty. Behav Neurosci 122: 140-150. CrossRef Medline

Reichel CM, Wilkinson JL, Bevins RA (2010) Reference place conditioning procedure with cocaine: increased sensitivity for measuring associatively motivated choice behavior in rats. Behav Pharmacol 21:323-331. CrossRef Medline

Shukla A, Beroun A, Panopoulou M, Neumann PA, Grant SG, Olive MF, Dong Y, Schluter OM (2017) Calcium-permeable AMPA receptors and silent synapses in cocaine-conditioned place preference. EMBO J 36:458-474.
Sinha R (2011) New findings on biological factors predicting addiction relapse vulnerability. Curr Psychiatry Rep 13:398-405. CrossRef Medline

Stefanik MT, Moussawi K, Kupchik YM, Smith KC, Miller RL, Huff ML, Deisseroth K, Kalivas PW, LaLumiere RT (2013) Optogenetic inhibition of cocaine seeking in rats. Addict Biol 18:50-53. CrossRef Medline

Stefanik MT, Kupchik YM, Kalivas PW (2016) Optogenetic inhibition of cortical afferents in the nucleus accumbens simultaneously prevents cue-induced transient synaptic potentiation and cocaineseeking behavior. Brain Struct Funct 221:1681-1689. CrossRef Medline

Stincic TL, Frerking ME (2015) Different AMPA receptor subtypes mediate the distinct kinetic components of a biphasic EPSC in hippocampal interneurons. Front Synaptic Neurosci 7:7. CrossRef Medline

Tomita S (2010) Regulation of ionotropic glutamate receptors by their auxiliary subunits. Physiology (Bethesda) 25:41-49. CrossRef Medline

Traynelis SF, Wollmuth LP, McBain CJ, Menniti FS, Vance KM, Ogden KK, Hansen KB, Yuan H, Myers SJ, Dingledine R (2010) Glutamate receptor ion channels: structure, regulation, and function. Pharmacol Rev 62:405-496. CrossRef Medline

Tzschentke TM (2007) Measuring reward with the conditioned place preference (CPP) paradigm: update of the last decade. Addict Biol 12:227-462. CrossRef Medline

Van den Oever MC, Spijker S, Smit AB, De Vries TJ (2010) Prefrontal cortex plasticity mechanisms in drug seeking and relapse. Neurosci Biobehav Rev 35:276-284. CrossRef Medline

Van Eden CG, Uylings HB (1985) Cytoarchitectonic development of the prefrontal cortex in the rat. J Comp Neur 241:253-267. CrossRef

Vertes RP (2004) Differential projections of the infralimbic and prelimbic cortex in the rat. Synapse 51:32-58. CrossRef Medline 